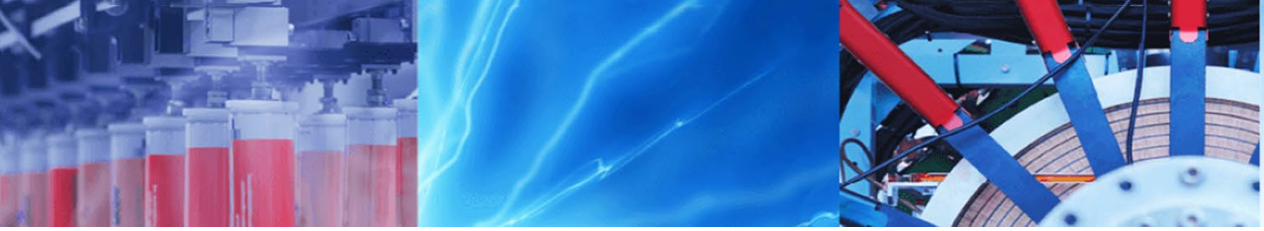

Research Article

\title{
Finite element modelling of interlocking stabilized laterite soil block walls
}

\author{
Sanewu Isaac Fundi ${ }^{1}$ James Wambua Kaluli ${ }^{2}$ John Kinuthia ${ }^{3}$
}

Received: 21 September 2020 / Accepted: 12 January 2021 / Published online: 27 January 2021

(C) The Author(s) 2021 OPEN

\begin{abstract}
This study sought to use the stress-strain relationship of interlocking stabilized soil block (ISSB) masonry to model its behaviour and develop empirical formulae to aid in predicting its compressive strength. A finite element (FE) analysis adopting the Rankine failure criterion was performed using Abaqus software to simulate the deformability behaviour of the wall which was validated through experimental tests. The compressive strength, modulus of elasticity and density of ISSB defined in the FE model were determined by performing laboratory tests on laterite soil blocks stabilized with pozzolanic cement, hydrated lime and rice husk ash. Conversely, the predictive empirical formulae for the compressive strength of the ISSB masonry was developed by performing statistical multiple regression analysis. In addition to the mechanical properties of masonry, the FE simulation results indicated that the deformability behaviour of ISSB masonry is influenced by the type of stabilizer used on the target material. This dictated the stress distribution and vertical displacement on the masonry. A diagonally stepped failure mode was experienced in more brittle masonry while cone failure mode was observed in less brittle masonry assemblage.
\end{abstract}

Keywords Dry stack masonry · Empirical equations · Finite element modelling · Interlocking soil blocks

\section{Introduction}

Masonry construction can be achieved either by using block units which are joined together using mortar or interlocking blocks that are dry stacked. Masonry is often assumed to be a homogeneous material in structural design analyses and building code specifications. Its true performance nature however, is determined by a complex interaction of the block units, mortar, grout, reinforcing steel (if present) and the magnitude of applied stress. Using the measured behaviour of the block units and mortar materials, the behaviour of masonry walls under compression has been discussed by several researchers [1, 2]. As noted by Fonseca et al. [3], development of tension on the block depends on the relative stiffness between the mortar and the unit while the crushing of the mortar depends on the relative strength between the mortar and the unit. Conversely, in interlocking stabilised soil block masonry, crushing of the wall depends of the unit stiffness and strength of the blocks. When conventional masonry is subjected to uniaxial compression, the stiff block units and the softer mortar layers generate triaxial stress as deformation is experienced. During deformation, the mortar is restrained by the brick units from lateral expansion and hence experience triaxial confinement, while the stiffer brick units are subjected to lateral tension. This therefore, dictates the failure of conventional masonry walls.

Interlocking stabilized soil blocks (ISSB) are produced using local suitable soils that are stabilized to improve their bearing capacity. Interlocking soil block load bearing

$\varangle$ Sanewu Isaac Fundi, fsanewu@gmail.com; ifundi@jkuat.ac.ke; James Wambua Kaluli, jkaluli@jkuat.ac.ke; John Kinuthia, kinuthia@ southwales.ac.uk| ${ }^{1}$ Jomo Kenyatta University of Agriculture Technology (JKUAT), P.O. Box 62000-00200, Nairobi, Kenya. ${ }^{2}$ Jomo Kenyatta University of Agriculture Technology, Nairobi, Kenya. ${ }^{3}$ University of South Wales, Pontypridd, UK. 
walls are normally made by laying block units next to each leaving no gaps. The performance of interlocking laterite soil blocks has been investigated under laboratory studies by Sanewu et al. [4]. The mode of failure under compression of ISSB masonry has been characterised by gradual formation of several diagonal cracks on the lateral sides of the wall [5]. It has further been reported by Carrasco et al. [6] that the loss of compression strength of the wall is considerable in relation to the block alone. ISSB masonry walls undergo inelastic deformations while sustaining their ability to withstand compressive loading. The stress-strain curve for ISSB masonry depicts three characteristic stages: (1) rapid compression load uptake, (2) crack propagation and (3) initiation of failure [7].

Since mechanical behaviour of masonry is complex and laboratory testing is time consuming; modelling can elaborate the behaviour at a considerable shorter time with less resources. As suggested by Lourenco et al. [8], use of numerical tools and modelling can predict the behaviour of a structure from linear stage, through cracking and degradation until complete loss of strength. Thus, hollow interlocking prisms were modelled by Hejazi et al. [9] to analyse their vulnerability against seismic excitation. In their study a finite element program was developed to model the wall under seismic loading. Since the loading was time dependent, a nonlinear analysis was followed. The study found that the maximum displacements of the walls exceeded the allowable displacement for masonry walls. In another study, Alwathaf et al. [10] proposed a stress-strain equation for simulating the load uptake of a grouted interlocking soil block masonry. Nonlinear regression analysis was used to fit the proposed equation to laboratory tested blocks. In their study they recommended that determination of a suitable material parameter for use in the equation can be used to simulate the stress-strain behaviour of masonry under compression for ascending and descending parts of the load uptake curve.

The strength of masonry is based on its compressive load carrying capacity, with the properties of the assemblage therefore, mainly influenced by the block stress-strain characteristics. Empirical formulae for mortar bonded masonry have been developed to enable prediction of its compressive stress-strain behaviour [11]. Under static loading conditions, empirical formulae can be used to predict masonry compressive strength though unsatisfactorily. As suggested by Tassios [12], Eqs. 1.1a, b can be used to estimate the compressive strength of a well-built mortar bonded brick masonry

$f_{w c}=\left[f_{m c}+0.4\left(f_{b c}-f_{m c}\right)\right] \cdot(1-0.8 \sqrt[3]{\alpha}), \quad f_{b c}>f_{m c}$ $f_{w c}=f_{b c} \cdot(1-0.8 \sqrt[3]{\alpha}), f_{b c}<f_{m c}$

where, $f_{w c}$ is masonry compressive strength, $f_{b c}$, and $f_{m c}$ are compressive strengths of individual block and mortar respectively, and $\propto$ is the ratio between average joint thickness and average block height. Eqs. 1.1a,b, however, do not take into account any existing interlocking nature of blocks or consider the type and amount of soil stabilizer used, thus limiting its application in ISSB masonry. According to masonry code of design [13], Eqs. 1.2 has been adopted in evaluating the compressive strength of mortar-bonded masonry wall

$f_{k}=\frac{f_{m}}{A} * \frac{\varphi_{u} \varphi_{m}}{1.2}$

where, $f_{k}$ is the compressive strength of masonry wall, $f_{m}$ is the mean of the maximum load carried by two test panels, $A$ is the cross-sectional area of each panel, $\varphi_{m}$ reduction factor for strength of mortar and $\varphi_{u}$ is the reduction factor for sample structural units. It is noted that Eqs. 1.1 and 1.2 consider the thickness and properties of the mortar that has been used to bond the blocks. These material properties are however not considered in the ISSB technology. Therefore, Eqs. 1.1 and 1.2 can only be used to determine the compressive strength of mortar bonded masonry. For ISSB masonry, there is need to develop mathematical equations that accurately depicts its performance by considering its assemblage unit properties.

Due to the structural difference of ISSB masonry from mortar bonded masonry, Uzoegbo and Ngowi [14] proposed Eqs. 1.3 for the determination of the average compressive strength of dry-stacked wall panel as a function of the masonry unit cube strength

$f_{\text {panel }}=\phi_{m} 0.15 f_{c u}+1$

where $f_{\text {panel }}$ is the compressive strength of dry-stacked panel, $\phi_{m}=0.9$ the safety factor for material used and $f_{c u}$ the masonry unit cube strength.

Uzoegbo and Ngowi [14] in developing Eq. 1.3, considered pozzolanic cement as the only stabilizing agent for interlocking soil blocks. Besides pozzolanic cement, it has been established by Sanewu et al. [4] that a blend of lime and rice husk ash with pozzolanic cement results to improved properties of interlocking blocks. It is from this back drop that empirical formulae considering alternative stabilizers have been developed.

There are two main approaches used to describe the structural response of masonry to loading: macro-modelling and micro-modelling [15]. According to Lourenco et al. [8], a detailed micro-model approach is normally adopted in representing masonry as a composite 
material consisting of block units and mortar joint. In the micro-modelling approach, the constituent units (mortar and blocks) are arranged in an average interface and lumped as discontinuous line interface elements. Thus, masonry is considered as a set of blocks bonded by potential slip lines at the joints.

The alternative macro-modelling approach does not make any distinction between masonry units and joints assuming formulation of a fictitious continuous material [16]. The masonry is considered as a homogeneous, anisotropic continuum with equivalent mechanical properties. Interlocking block masonry utilizes nearly zero-thickness interface at the joints enabling the materials to be of one form. The macro-model approach was therefore considered appropriate for this study since it is more practice oriented and the masonry was considered as a smeared homogeneous medium.

The ISSB are manufactured from clay products thus they can be categorised as brittle materials. The material properties of earth products that enable them to remain in equilibrium when forces are acting to break them have been established by Langenbach [17] to be shear strength and tensile strength. According to Horri and Nasser [18], inelastic deformation in brittle materials may lead to the following failure modes depending on the magnitude of confining pressure: (1) axial splitting of the sample by microscopic cracks extending in the direction of axial compression, in the absence of any lateral confining pressure; (2) faulting, when axial compression is accompanied by moderate confining pressure; and (3) ductile flow in the presence of a suitably large confining pressure. When unconfined masonry is subjected to compression loading, it may fail under the first two modes when stress exceeds the yield point of the material. The high-energy stress values required to cause the failure are provided by stress concentration introduced by small pre-existing cracks in the material [19]. When this process becomes unstable, the brittle material separates over a large area causing failure. Therefore, the material failure theory best suited in predicting the failure of brittle materials has been found by Silva [20] to be the maximum principal stress theory. Therefore, to model the failure of the ISSB masonry under compression, the Rankine yield criterion (Fig. 1) has been suggested by Lourenco [21] for masonry specimen subjected to biaxial test with the angle $a=0^{\circ}$.

In this study, finite element modelling following the Rankine failure criterion was performed using Abaqus software to simulate the deformability behaviour of the ISSB wall. On the other hand, the ISSB masonry stress-strain relationship were also used to develop empirical formulae to aid in predicting the compressive strength of ISSB wall. The regression analysis formulae considered the amount and type of soil stabilizer used.

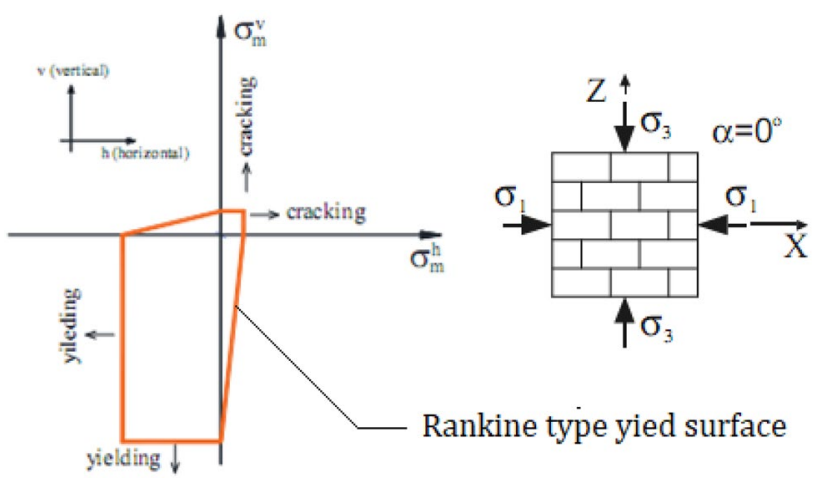

Fig. 1 Generalised failure criterion of Rankine for masonry wall

Table 1 Physico-mechanical properties of stabilized laterite soil blocks

\begin{tabular}{llll}
\hline Block type & \multicolumn{3}{l}{ 28-Day block properties } \\
\cline { 2 - 4 } & $\begin{array}{l}\text { Compressive } \\
\text { strength (MPa) }\end{array}$ & $\begin{array}{l}\text { Water absorp- } \\
\text { tion (\%) }\end{array}$ & $\begin{array}{l}\text { Abraded } \\
\text { material } \\
(\%)\end{array}$ \\
\hline 6\%PC & 3.46 & 12.41 & 0.58 \\
6\%PC1\%L & 3.67 & 12.54 & 0.49 \\
6\%PC2\%L & 3.41 & 11.91 & 0.33 \\
6\%PC3\%L & 4.03 & 14.78 & 0.41 \\
6\%PC4\%L & 3.98 & 11.94 & 0.27 \\
6\%PC1\%RHA & 2.93 & 8.61 & 0.49 \\
6\%PC2\%RHA & 2.82 & 9.84 & 0.23 \\
6\%PC3\%RHA & 1.62 & 11.60 & 0.37 \\
6\%PC4\%RHA & 2.53 & 10.15 & 0.43 \\
\hline
\end{tabular}

\section{Materials and methods}

\subsection{Fabrication of blocks and wall panels}

Interlocking soil blocks (dimensions $220 \mathrm{~mm}$ long $\times 220 \mathrm{~mm}$ wide $\times 120 \mathrm{~mm}$ high) were made of laterite soil consisting of $25 \%$ fine gravel and $75 \%$ sand. Pozzolanic cement $(\mathrm{PC})$, hydrated lime $(\mathrm{L})$ and rice husk ash (RHA) were used in combinations as stabilizers. Tests were conducted on individual blocks in accordance to KS 021070 [22]. Table 1 reports the laboratory tests of individual stabilized soil blocks.

Three types of wall models (two specimens of each), LSW1 (PC only), LSW2 (L-PC blend), and LSW3 (RHA-PC blend) were considered for the experimental analysis. Construction of the walls was performed by stacking the blocks while utilising their interlocking capacity. Horizontal and vertical alignment of the walls were checked using a straight piece of timber during the construction 
of each course. A grooved steel plate was placed at the top course to cover the block projection and uniformly distribute the load. Since the wall was constructed with blocks cured for 28 days, they were ready for testing immediately after construction. To test the wall, an increasing compression load was applied through a 50-tonne load cell that was connected to a data logger to record the resistance values. The wall vertical displacement was measured using linear variable differential transducer. During compression loading, the walls were not constrained at the vertical ends. The laboratory set up of the wall is shown in Fig. 2.

The density of interlocking blocks was measured gravimetrically, while the Poisson ratio $(u=0.35)$ was deduced from recorded values of axial and transversal strains. The blocks'Young's modulus was derived from the stress-strain curves of the 28-day compression experimental test. The value was set to be approximately equal to the slope of the stress-stain curve. The basic properties for ISSB masonry (compressive strength, modulus of elasticity, density and Poisson's ratio) as obtained in the laboratory test are reported in Table 2.

\subsection{Regression analysis of compressive strength data}

Regression analysis was carried out using Statistical Package for the Social Sciences (SPSS) version 20. Multiple regression gave the opportunity to establish interdependence of variables. In this case, the independent variables were block compressive strength, type of stabilizer and stabilizer content while the dependent variable was the wall compressive strength. The analysis considered a relationship between the compressive strength of the wall to that of individual blocks as contributed by the type and amount of stabilizer content.

\subsection{Finite element modelling methodology}

A numerical simulation of the structural response of the wall to compressive and horizontal loading was performed using Abaqus CAE 6.14-1 version. Since the ISSB masonry units were dry stacked without use of joining mortar, the wall components were discretized using a three -dimensional deformable solid of 8-nodded element (C3D8R) as a homogeneous continuum without intermediate layers. A standard 8-node plane element with reduced integration was chosen based on the macro-model approach. The geometry of the assembled parts was defined by creating independent instances for analysis. For the study model; load and boundary conditions were not rate dependent. For this purpose, linear static analysis procedure was used. A second-order element consisting of a global seed size of
20 was considered. The mesh size was selected based on the model size limits of the Abaqus Standard/Explicit product [23]. The wall model was $1200 \mathrm{~mm}$ long and $900 \mathrm{~mm}$ high. The model assumed no imperfections at the point of loading.

The combination of mortar and stone in conventional masonry results to a material with anisotropic characteristics in elastic-plastic condition. However, the consideration of interlocking soil block as a homogenous material eliminating the block-to-mortar interaction makes its deformation unvarying under loaded state. Tarque et al. [24] further argue that adobe masonry behaves well under compression but can only resist low tensile stresses with a quite brittle post-peak tensile behaviour. They noted that since adobe bricks and the mortar are composed of mud, both can be assumed as a homogeneous material. This study utilised dry stacked interlocking soil blocks without mortar. Therefore, the ISSB wall was modelled using elastic-plastic constitutive material model, implementable in the Abaqus program as a homogenous material. Consequently, the model was based on anisotropic plasticity theory using the standard Rankine yield surface with assorted plastic flow since the masonry was considered brittle. The wall model properties defined in the FE model were in line with the results of the experimental tests. Figure $3 a, b$ show the model wall set up and the generated mesh of the modelled wall.

The steel I-section acting as the load spreader beam was modelled as a linear elastic material with mechanical properties obtained from documented literature as: density $(\rho) 7850 \mathrm{~kg} / \mathrm{m}^{3}$, Poisson ratio ( $(\mathrm{)}) 0.30$, and Young's modulus (E) $205 \mathrm{GPa}$. Since the wall was constructed on a concrete floor, the bottom course of the wall was considered continuously simply supported along the entire surface. The bottom course was therefore modelled with pinned boundary condition constraining the three structural degrees of freedom at the connection (Fig. 3a). The maximum compressive strength sustained by the experimental walls was assigned to the upper steel plate as uniformly distributed load.

\section{Results and discussion}

\subsection{Interlocking block compressive strength from regression analysis}

Masonry compressive strength has been addressed in codes of design for ordinary masonry blocks. However, as a result of different performance of interlocking soil blocks due to absence of mortar layer, this research proposes alternative empirical formulae to be utilised in ISSB construction. The proposed equations predict the 28-day 


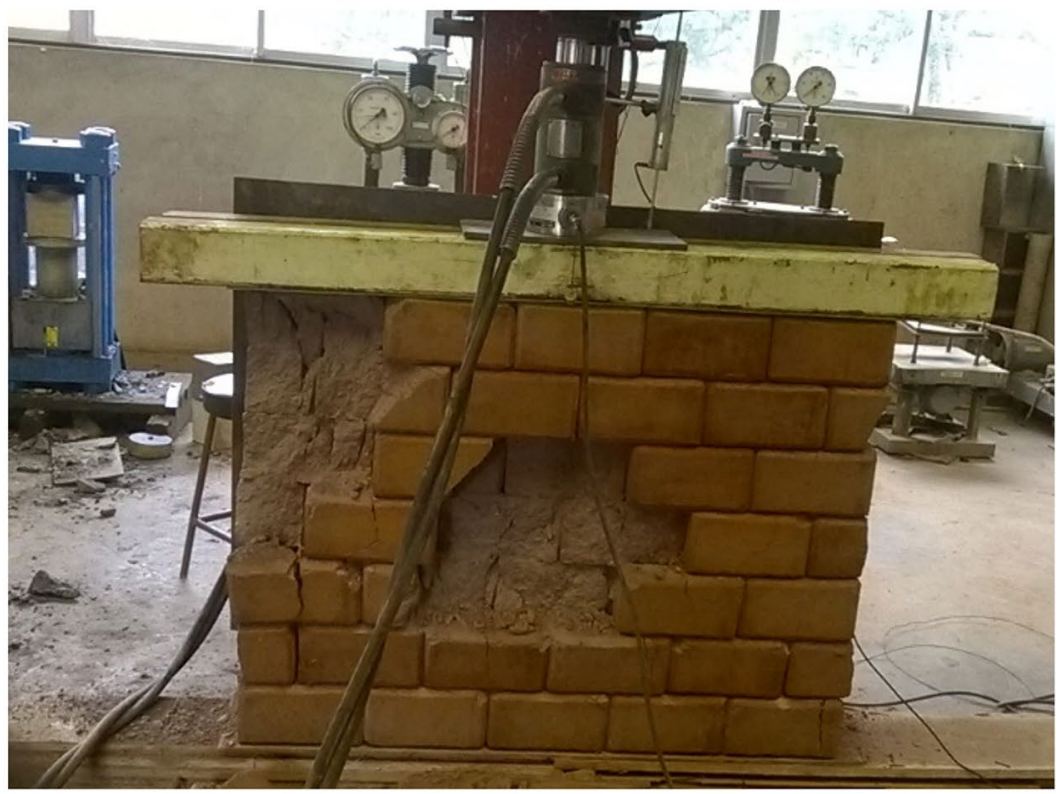

a Horizontal view of the wall

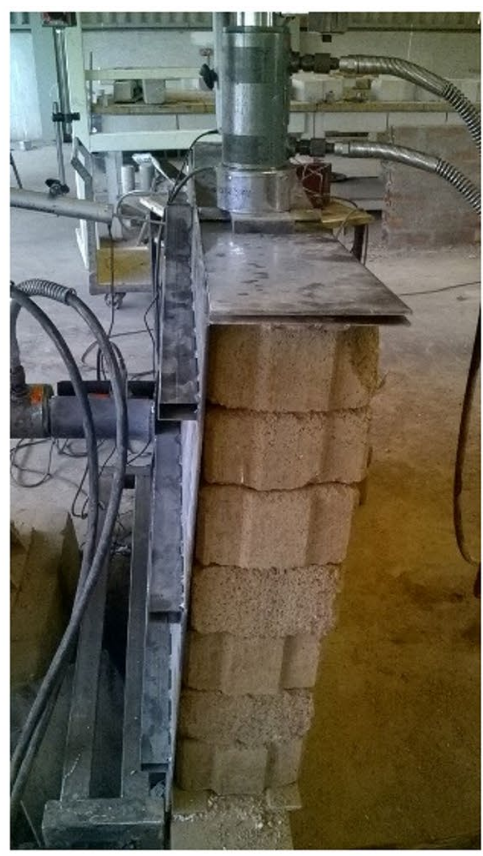

b Breadth view of the wall

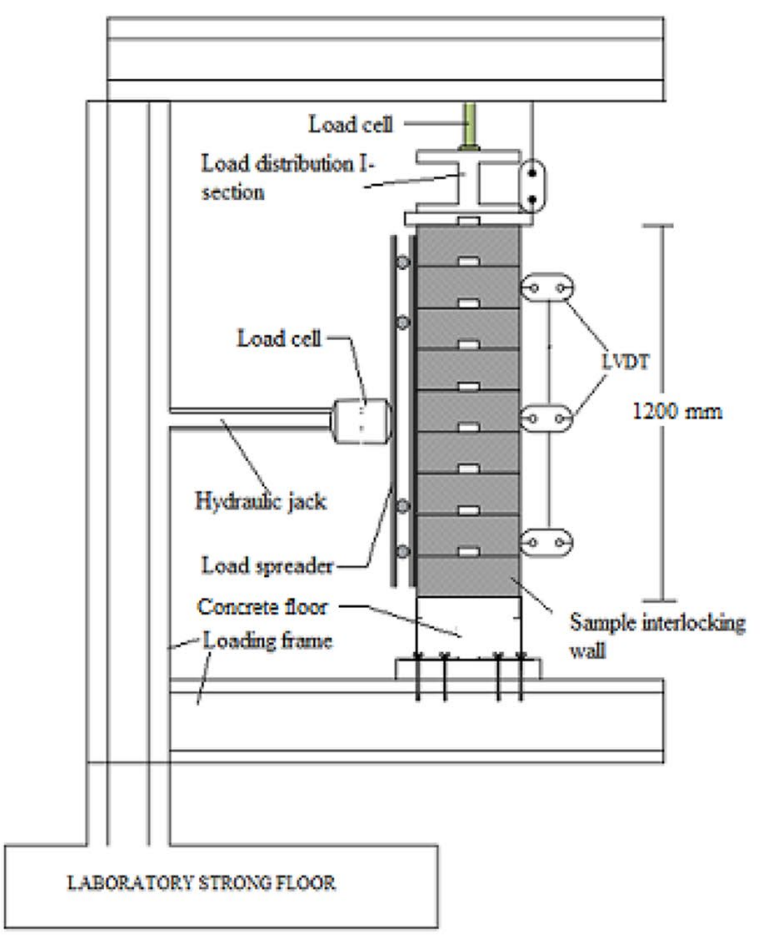

c Schematic representation of the experimental wall

Fig. 2 Experimental set up of the dry stack wall 
Table 2 Interlocking soil block and wall properties

\begin{tabular}{llllll}
\hline Wall type & $\begin{array}{l}\text { Block density } \\
\left(\mathrm{kg} / \mathrm{m}^{3}\right)\end{array}$ & $\begin{array}{l}\text { Young's modu- } \\
\text { lus (MPa) }\end{array}$ & Poisson's ratio & $\begin{array}{l}\text { Max. wall compres- } \\
\text { sive strength }(\mathrm{MPa})\end{array}$ & $\begin{array}{l}\text { Wall vertical } \\
\text { deflection } \\
(\mathrm{mm})\end{array}$ \\
\hline LSW1 & 1878 & 3850 & 0.35 & 0.9 & 40 \\
LSW2 & 1981 & 4796 & 0.35 & 1.1 & 36 \\
LSW3 & 1900 & 4477 & 0.35 & 1.1 & 39 \\
\hline
\end{tabular}

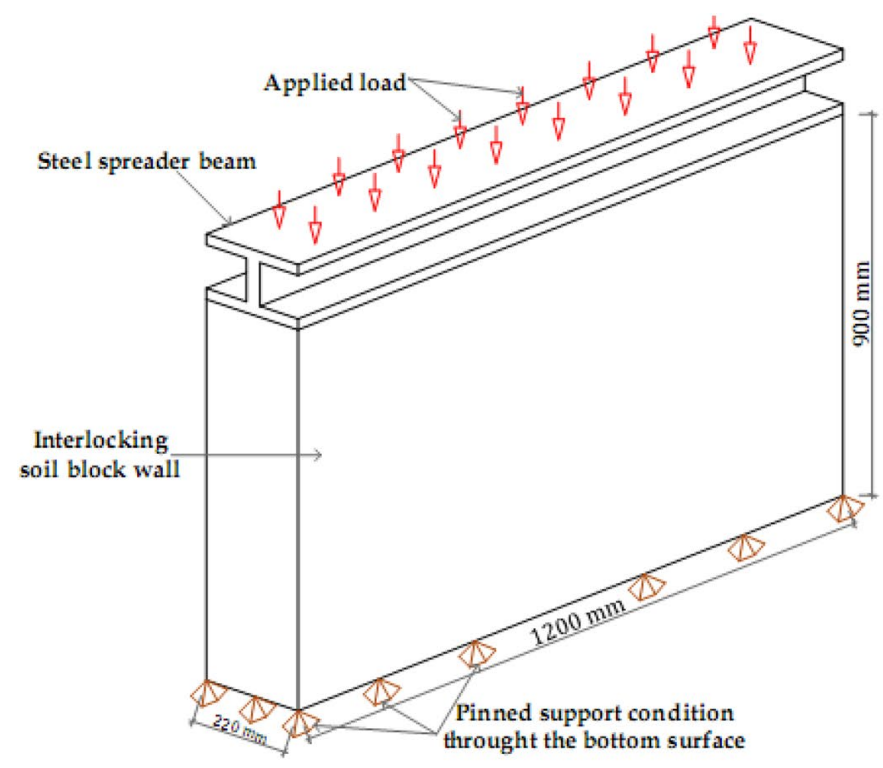

a Model wall set up

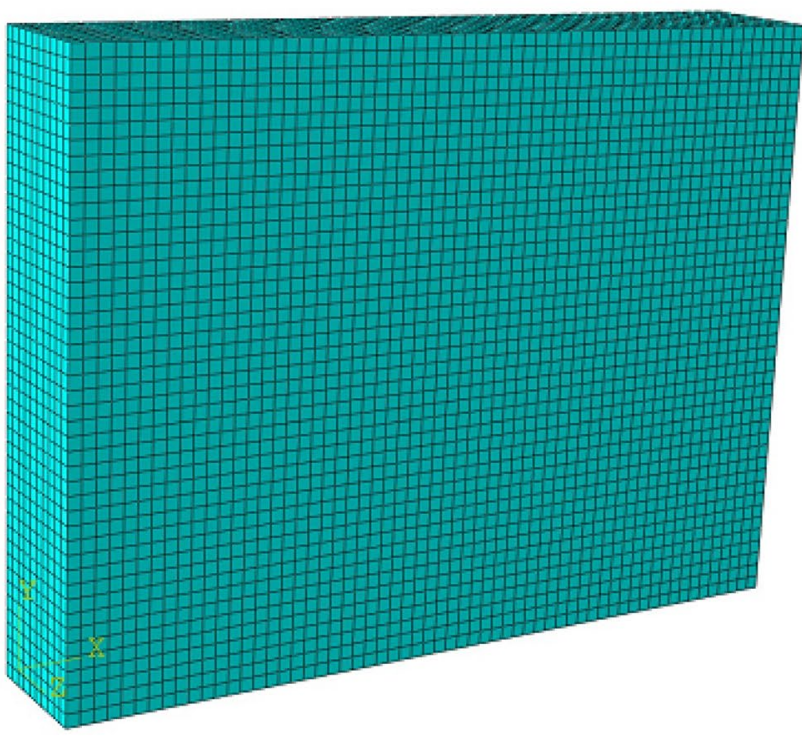

b Generated mesh on modelled wall

Fig. 3 Schematic of the modelled wall

compressive strength of the blocks while considering the different blends of stabilizers. Since the blocks were stabilized differently, two cases were probable considering the blends of the stabilizing agents.

\subsubsection{Case 1: Cement and lime stabilized laterite soil}

The interlocking block compressive strength as established in this research (Eq. 3.1)considered the contribution of pozzolanic cement and lime content in laterite soil. From laboratory results, pozzolanic cement was varied from 4.8 to $6 \%$ at intervals of 0.2 while lime varied from 0 to $5 \%$ at unit intervals. The regression analysis adjusted $R^{2}$ coefficient $(0.895)$ indicated a strong relation between the variables and the response value (block compressive strength). Equation 3.1 predicts block strength with a pozzolanic cement content equal to or greater than $4.8 \%$. Besides having a strong corelation as indicated by Eq. 3.1, the equation performs predictions of the compressive strength much more quickly with higher defined confidence intervals corresponding to experimental outputs. $f_{c b 1}=2.283\left(c-\frac{3 l}{761}\right)-9.995$ forc $\geq 4.8 \%$

where $f_{c b 1}$ is the interlocking block mean compressive strength (MPa), $c$ is the pozzolanic cement content in percentage of dry weight of laterite soil ( $\geq 4.8 \%$ ), and $/$ is lime percentage of dry weight of laterite soil.

\subsubsection{Case 2: Cement and RHA stabilized laterite soil}

Multiple regression analysis was performed on laboratory collected data for blocks stabilized with a blend of pozzolanic cement and RHA. In this case pozzolanic cement content was maintained at $6 \%$ while RHA was varied from 0 to $6 \%$ at unit intervals. The empirical equation for compressive strength of blocks containing a combination of $6 \%$ cement and variation of RHA $\left(f_{c b 2}\right)$ is as shown in Eq. 3.2. The RHA value of regression analysis adjusted $R^{2}=0.460$ indicated a wide variation between the dependent variable (block compressive strength) and the independent variables (RHA and cement content). This suggests that a proportional factor 
needs to be included in the predictive equation in order to reliably predict the compressive strength.

$f_{c b 2}=3.109-0.257$ rwith $6 \% \mathrm{C}$

where $r$ is RHA percentage of dry weight of laterite soil.

To estimate the compressive strength-stabilizer content effect, Fig. 4 was plotted. The best fit equation trends as predicted by Eqs. 3.1 and 3.2 against experimental data of ISSB are shown in Fig. 4. The trend in Fig. 4a matches well and is in good agreement with the experimental results as compared to the trend in Fig. 4b. The empirical Eq. 3.2 could not capture the peaks as the quantity of RHA was increased in laterite soil. From the results, it can be concluded that Eq. 3.2 can only represent the overall compressive strength development in laterite soil blocks stabilized with RHA.

\subsection{Interlocking block wall compressive strength}

The formulation of the prediction functions for compressive strength of the walls considered the three types of experimental walls to obtain the relationship between the block and the wall capacity. The characteristic compressive strength's $\left(f_{c w}\right)$ for wall type LSW1 (PC only) and LSW2 (L-PC blend) from multiple linear regression are expressed in Eqs. 3.3 and 3.4 respectively.

$f_{c w 1}=219.07 f_{c b}-114.44$

$f_{c w 2}=2.64 f_{c b 1}+0.08$

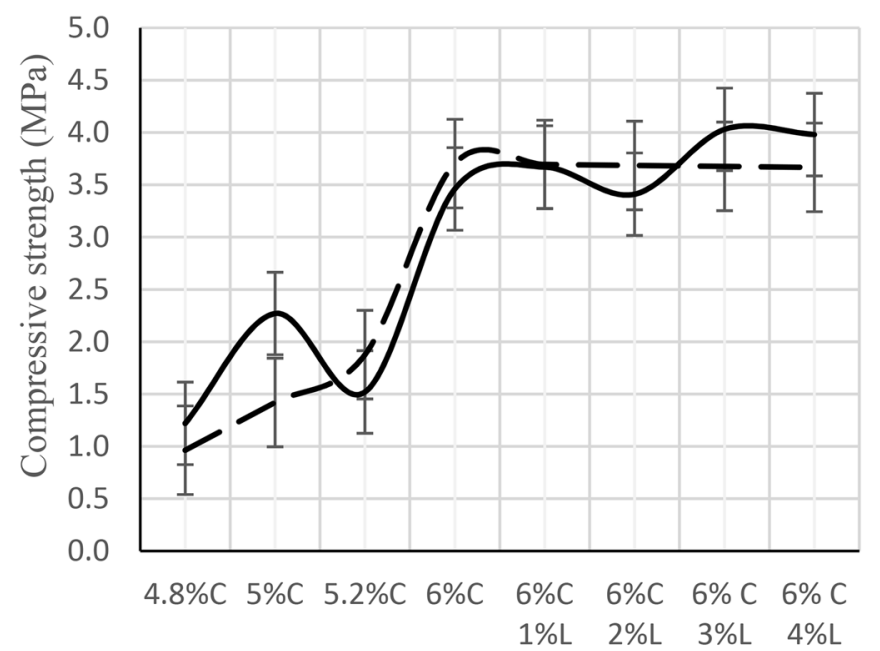

Stabilizer content in laterite soil (\%)

$$
\text { - Experimental — Empirical }
$$

a Cement and lime stabilized laterite soil
The compressive strength prediction function for type LSW3 (RHA-PC blend) obtained from the individual blocks (Eq. 3.5) incorporates RHA quantity with $6 \%$ cement.

$f_{c w 3}=0.38 f_{c b 2}+0.02$

The developed empirical formulae reveal that the predicted compressive strength of interlocking blocks depends on different parameters (stabilizer type, quantity and blend of stabilizers) in addition to what was adopted by Uzoegbo and Ngowi [14]. Sajanthan, Balagasan and Sathiparan [25] argue that even though masonry compressive strength depends on masonry units and the interfacial bond between masonry units, the behaviour of masonry as a unit contributes to resistance of the compressive strength. Since the dependent variable considered in this study was reliant on several independent variables, the functional output of the equations is reliable due to its consideration of multiple dependencies.

\subsection{Finite element simulation results}

The non-linear stress-strain and failure mode behaviour of the interlocking masonry wall was simulated using the Rankine failure criterion in the Finite Element (FE) model. The simulation followed the maximum principal stress theory where failure was considered to occur once the elastic limit stress in simple tension was reached.

A good agreement was found on failure mode of experimental results and the stress distribution

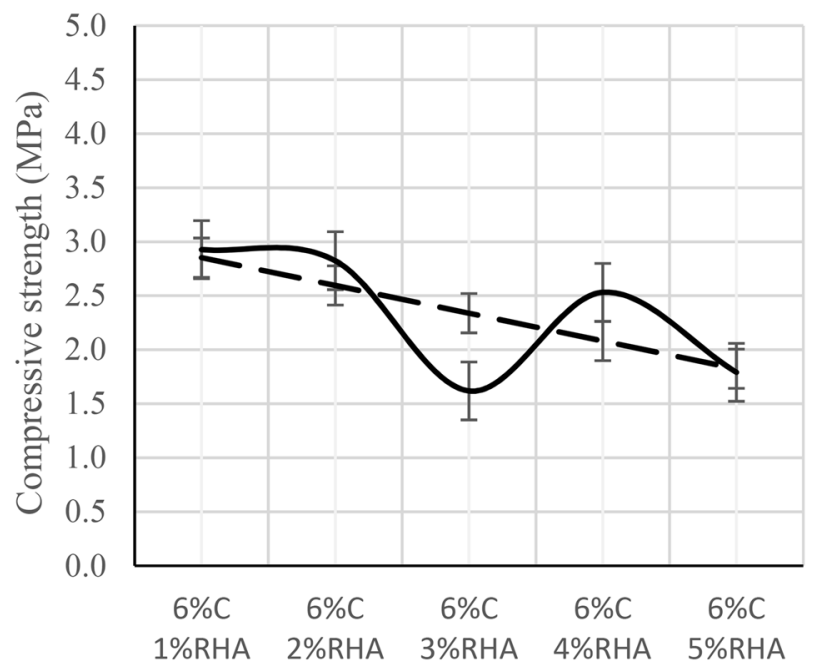

Stabilizer content in laterite soil (\%)

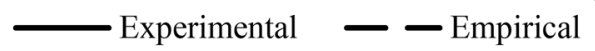

b Cement and RHA stabilized laterite soil

Fig. 4 Comparison of block experimental compressive strength results with empirical equation 

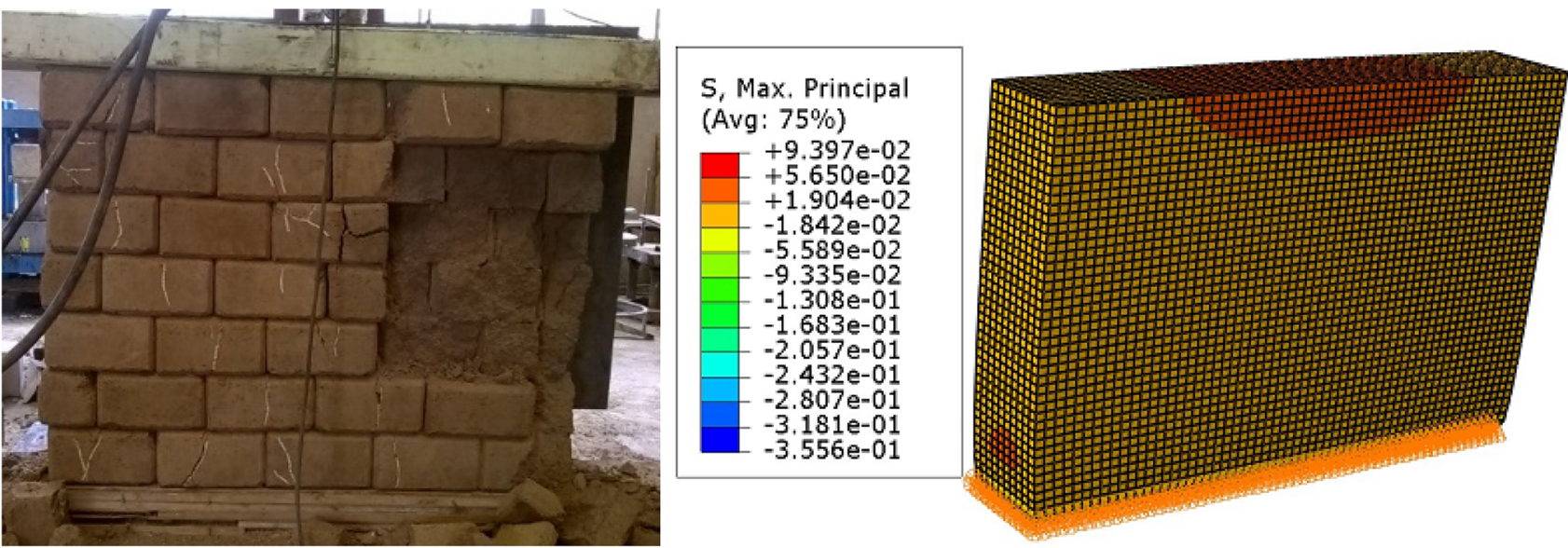

a Failure mode of experimental wall (LSW1) b Maximum principal stress distribution

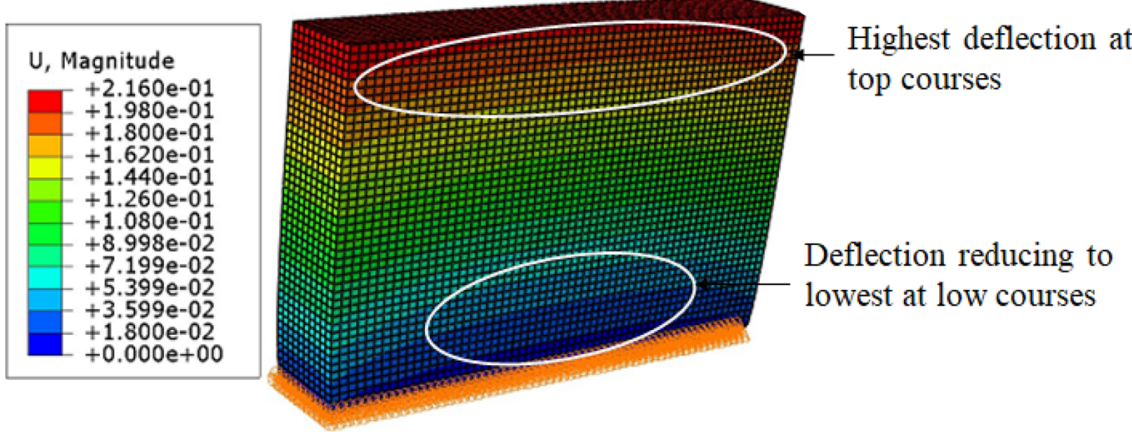

c Finite element wall displacement

Fig. 5 Maximum principal stress and load displacement distribution in LSW1 masonry

expressed by FE simulation of the LSW1. The results show that the observed experimental wall failure behaviour (Fig. 5a) is governed by principal stresses distribution as shown by the contours in Fig. $5 \mathrm{~b}$. It is observed in the FE simulation results (Fig. 5b), that the block-load interface layer at the top central regions is subjected to maximum stress (0.94 $\mathrm{MPa}$ ). The ultimate compressive stress recorded in experimental analysis $(0.90 \mathrm{MPa})$ was however marginally lower than in numerical simulation. This finding concurred with the observation by Sadoun [26], who found that the load carrying capacity from FE analysis of Putra Block was relatively higher than that obtained from test results. He argued that this was due to neglection of the material and geometrical nonlinearity and initial imperfection in FE modelling.

The FE simulation indicated that LSW1 allowed higher compression displacement at the top block layers than the bottom layers (Fig. 5c). The displacement at the bottom layers was higher at the corners and increased vertically upwards at the central bottom courses. These small compressive strains resulted to constraining of the blocks at this region leading to initiation of cracks as observed in the experimental wall (Fig. 5a).

The experimental results of LSW2 depicted spalling of block debris in a diagonally stepped failure mode (Fig. 6a). The maximum principal stress distribution from FE showed a conical failure through the wall (Fig. 6b). The maximum principal stress contour spread at an inclined angle to the central region of the middle courses of the wall, then outwards to the bottom corners. The diagonally oriented failure of the experimental wall matched the inclined contour path to the bottom corner of the wall. This observation was in line with Horri and Nasser [18] findings. They have shown that, under axial compression, tension cracks initiate at an angle close to 70 degrees to fault orientation in brittle material. These cracks grow resulting to axial splitting. The model results indicate that maximum stresses are experienced at the top courses with blocks at the bottom central position experiencing the lowest stresses. The maximum stress recorded by numerical analysis was $1.38 \mathrm{MPa}$ compared to $1.1 \mathrm{MPa}$ recorded from experimental results. 

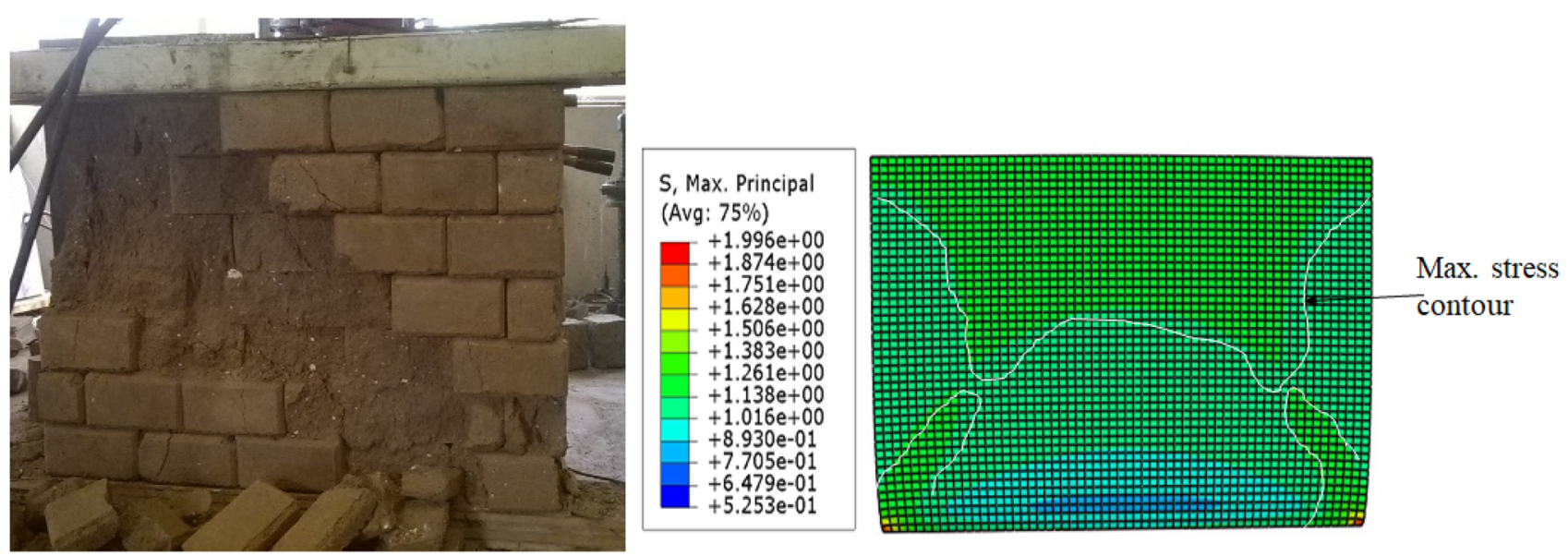

a Failure mode of experimental wall (LSW2)

b Maximum principal stress distribution
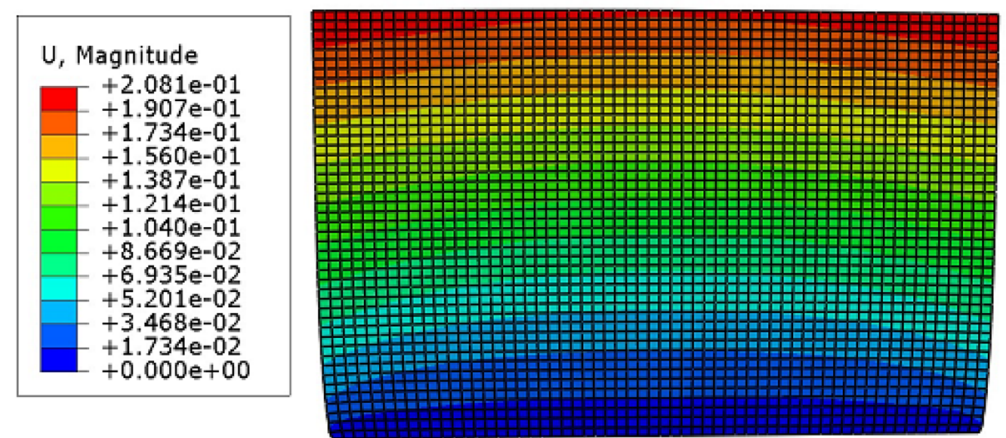

c Finite element wall displacement

Fig. 6 Maximum principal stress distribution in LSW2 masonry

The model results depict higher vertical displacements at the top courses which reduces downwards. From the results it is clear that the vertical edges of the wall deflected more than the central sections (Fig. 6c). Compared to LSW1, the FE results indicate no change of deflection behaviour of the walls when loaded to failure. However, there is a change of failure mode from compression failure experienced in LSW1 to diagonal stepped compression in LSW2. There was also an increased stress carrying capacity in LSW2 panels.

It can be implied from these results that the compression capacity and failure mode of ISSB wall is dictated by the distribution of maximum principal stresses on the wall which was influenced by the characteristics of the stabilizing agent used. This clearly indicates that stress distribution is influenced by composition of the constituent material (in this case, type of target material and stabilizer used) which further determines how the wall sustains the applied stress. Further, it is clear from the results, that crushing failure mode leads to lower stress carrying capacity as compared to conical failure mode of
ISSB. Conical failure mode results to sustenance of higher applied loading no the masonry wall.

The initiation of cracks was at the top courses in the experimentally tested LSW3. The crack widths and intensity increased as they spread to the bottom courses (Fig. 7a). As can been seen from Fig. 7b, the maximum compressive stress (1.19 MPa) occurred at the central top courses of the wall. Other sections of the wall experienced a uniform distribution of stresses, with compressive stresses at the bottom course. There was no vertical deformation that was recorded at the bottom courses of the wall (Fig. 7c). This restriction of deformation on blocks may have resulted to cracking of the units as observed in the experientially tested wall. Maximum vertical deflection of $23.53 \mathrm{~mm}$ was achieved on the top courses. It is noted that blocks stabilized with lime deflected the least and sustained the highest compressive stress, as compared to its RHA stabilized equivalents. Arroyo et al. [27] suggested that natural soils can be deformed highly under loading than stabilized one. They further argued that volumetric compression is not experienced much due to cementation 


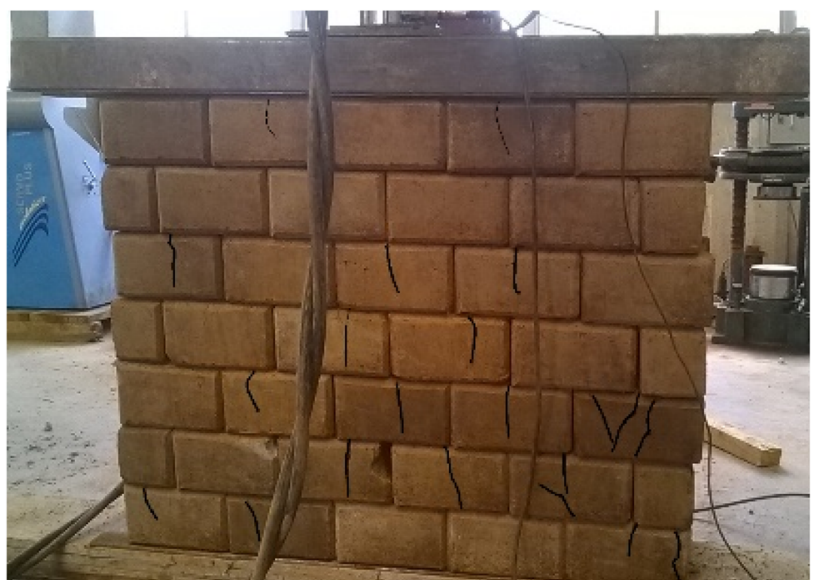

a Failure mode of experimental wall (LSW3)
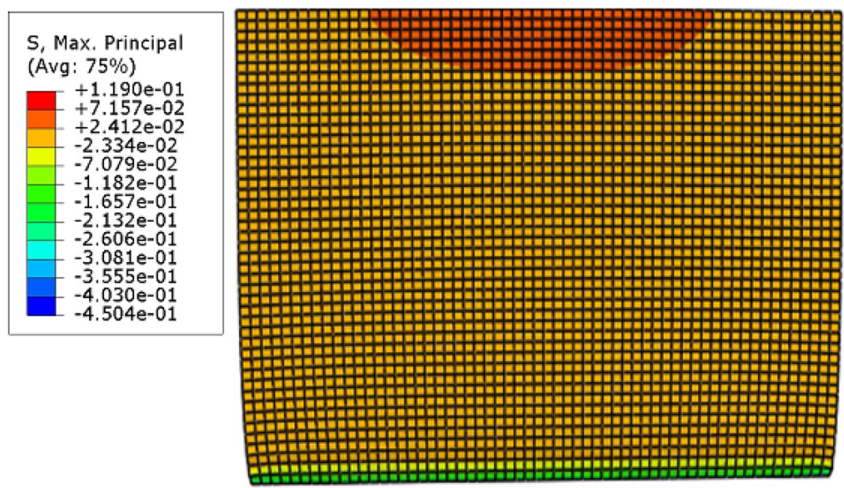

b Maximum principal stress distribution
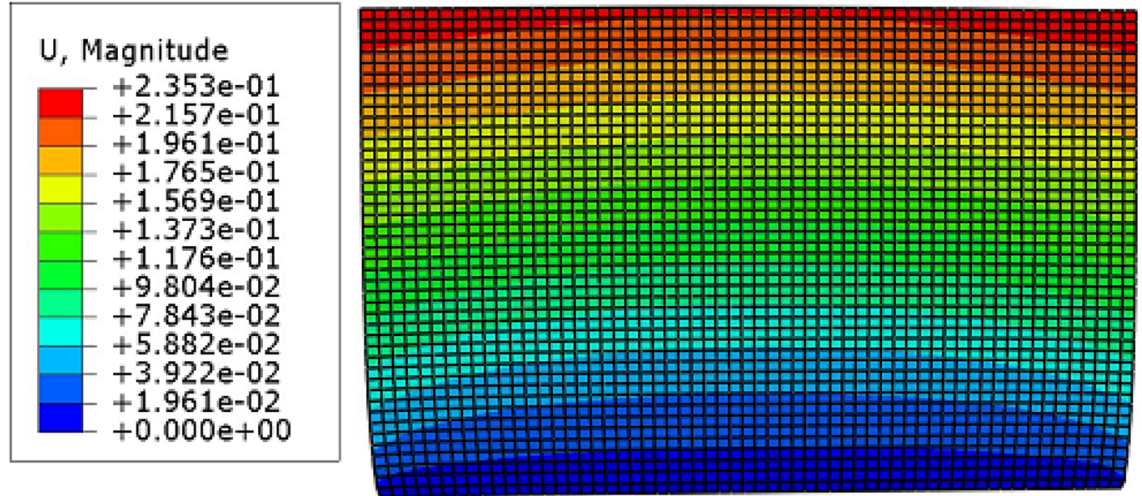

c Finite element model wall displacement

Fig. 7 Maximum principal stress distribution in LSW3 masonry

and hardening of the soil making it brittle. In this study, the degree of brittleness (as suggested by the vertical deflection) of the wall may have contributed to the mode of failure of the ISSB panel.

Overall, the FE model walls experienced less vertical deflection as compared to the experimental walls. Vertical deflection due to flattening process of the dry joint has been examined by Marzahn and Koning [28] by placing a sheet of carbon paper in between two dry stack blocks. They concluded that most of the deformations are caused by the geometric imperfection at the contact surface of the dry joint. Since no imperfections were assumed in the model, this contributed to smaller vertical deflection.

\section{Conclusion}

In this study, ISSB masonry behaviour was evaluated using finite element modelling and multiple regression analysis. The research focused on predicting the compressive strength of interlocking block masonry and verifying stress contribution on its mode of failure. Based on the finite element results and multiple regression analysis, the following conclusions can be stated:

- The total behaviour and failure pattern of ISSB masonry is influenced by the type of stabilizer used on the target material which dictates the stress distribution and vertical displacement of the masonry.

- From the regression analysis, simple relationships have been identified that can predict quickly compressive strength for the interlocking stabilized soil block and masonry from their stabilizers.

- Finite element model results showed a fair agreement with tested wall panels in regard to the failure mode. The results indicated that a diagonally stepped failure mode is experienced in more brittle masonry assemblage while cone failure mode occurs in less brittle assemblage.

- Compressive strength of laterite soil block walls stabilized with a blend of lime and pozzolanic cement was fairly estimated using the developed empirical 
formulae. However, replacement of lime with RHA in the empirical equation reduced the correlation of the compressive strength to its quantity.

\section{Compliance with ethical standards}

Conflict of interest On behalf of all authors, the corresponding author states that there is no conflict of interest.

Open Access This article is licensed under a Creative Commons Attribution 4.0 International License, which permits use, sharing, adaptation, distribution and reproduction in any medium or format, as long as you give appropriate credit to the original author(s) and the source, provide a link to the Creative Commons licence, and indicate if changes were made. The images or other third party material in this article are included in the article's Creative Commons licence, unless indicated otherwise in a credit line to the material. If material is not included in the article's Creative Commons licence and your intended use is not permitted by statutory regulation or exceeds the permitted use, you will need to obtain permission directly from the copyright holder. To view a copy of this licence, visit http://creativecommons. org/licenses/by/4.0/.

\section{References}

1. Atkinson RH, Noland JL (1983) "A proposed failure theory fro brick masonry in compression". Proceeding, 3rd Canadian Masonry Symposium, Edmonton, pp 5.1-5.17

2. Ahmed Z, Othman S, Yunus B, Mohamed A (2011) Behaviour of masonry wall constructed using interlocking soil cement bricks. World Acad Sci Eng Technol 60:1263-1269

3. Fonseca FS, Mohamad G, Roman HR, Vertmeltfoort A, Rizzatti $\mathrm{E},(2015)$ "Deformation and failure mode of masonry". In 12th North American Masonry Conference, 17-20 may 2015, Denver, Colorado pp. 1-12

4. Sanewu IF, Kaluli JW, Kinuthia J (2018) Performance of interlocking laterite soil block walls under static loading. J Construct Build Mater 171:75-82

5. Illampas R, loannou I, Charmpis DC (2011) A study of the mechanical behaviour of adobe masonry. WIT Trans Built Environ 118:485-496

6. Carrasco EV, Mantilla JN, Esposito T, Moreira LE (2013) Compression performance of walls of interlocking bricks made of iron ore by-products and cement. Int J Civil Environ Eng 13(3):56-62

7. Fundi IS, Kaluli JW, Maritim NK, Kabubo CK (2014) Effects of municipal solid waste ash on the strength of earthen bricks and walls. J Agric Sci Technol 16(2):140-155

8. Lourenço PB, Rots JG, Blaauwendraad J (1995) Continuum model for masonry: parameter estimation and validation. $J$ Struct Eng 124(6):642-652
9. Hejazi F, Noorzaei J, Ali AA, Jaafar MS (2015) Seismic analysis of interlocking mortarless hollow block. Chall J Struct Mech 1(1):22-26

10. Alwathaf AH, Jaafar MS, Thanoon WA, Noorzaei J (2011) “Stressstrain relationship for masonry modelling". The international building and infrastructure technology conference, Penang, Malaysia

11. Magenes G, Menon A (2009) A review of the current status of seismic design and assessment of masonry buildings in Europe. J Struct Eng SERC 35(6):247-256

12. Tassios TP (2010) Seismic engineering of monuments. Bull Earthq Eng 8(6):1231-1265

13. British Standards Institution (BSI)., BS 5628-1, "Code of practice for use of masonry; structural use of unreinforced masonry", (2002).

14. Uzoegbo HC, Ngowi JV (2003) Structural behaviour of dry-stack interlocking block walling system subjected to in-plane loading. Johannesburg, South Africa

15. Milani G, Lourenço PB, Tralli A (2006) Homogenised limit analysis of masonry wall, part I: failure surface. Comput Struct 84(3-4):166-180

16. Lourenço PB, Rots JA (1997) A multi-surface model for the analysis of masonry structures. J Eng Mech ASCE 123(7):660-668

17. Langenbach R (1992) Earthquakes: a new look at cracked masonry. Civil Eng ASCE 62:56-58

18. Horii H, Nasser SN (1986) Brittle failure in compression: splitting, faulting and brittle-ductile transition. Phil Trans R Soc Lond 319:337-374

19. Renshaw CE, Schulson EM (2001) Universal behavior in compressive failure of brittle materials. Nat Int J Sci 412:897-900

20. Silva DV (2006) Mechanics and Strength of Materials. Springer, NY

21. Lourenco PB (1996) "Computational strategies for masonry structures". Dissertation, Delft University of Technology, Delft, The Netherlands

22. Kenya Bureau of Standards (KEBS) (1993) "Specifications for stabilized soil blocks", KS 02-1070, Nairobi.

23. Dassault Systems, "Abaqus analysis user's manual 6.13-3. R12013; Dassault Systems providence Witham, USA

24. Tarque N, Spacone E, Blondet M, Varum H (2012) "The use of continuum models for analyzing adobe", World Conference on earthquake engineering

25. Sajanthan K, Balagasan B, Satiparan N (2019) Prediction of compressive strength of stabilized earth blok masonry. Adv Civil Eng 2019:1-13

26. Sadoun, I.S., "Finite element analysis of interlocking load-bearing Hollow block", Master of Science Thesis, University of Putra Malaysia, (2000).

27. Arroyo M, Amaral F, Romero E, Viana A (2013) Isotropic yielding of unsaturated cemented silty sand. Can Geotech J 50:807-819

28. Marzahn G, Koning G (2002) Experimental investigation of longterm behavior of dry-stacked masonry. Masonry Soc J 50:9-22

Publisher's Note Springer Nature remains neutral with regard to jurisdictional claims in published maps and institutional affiliations. 